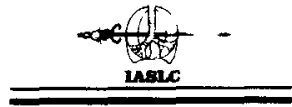

\title{
Pretreatment minimal staging for non-small cell lung cancer: an updated consensus report is
}

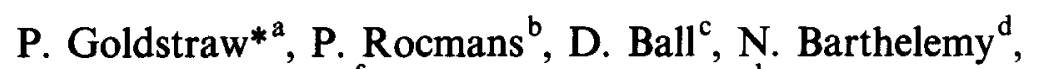
J. Bonner ${ }^{\mathrm{e}}$, M. Carette $\mathrm{f}^{\mathrm{f}}, \mathrm{N}$. Choi ${ }^{\mathrm{g}}$, B. Emami ${ }^{\mathrm{h}}$, D. Grunenwald ${ }^{\mathrm{i}}$, M. Hazuka ${ }^{j}$, D. Ihde ${ }^{k}$, J. Jassem ${ }^{1}$, G. Kho ${ }^{m}$, T. Le Chevalieir ${ }^{n}$, M. Monteau ${ }^{\circ}$, G. Storme ${ }^{\text {p }}$, S. Wagenaar ${ }^{q}$

\footnotetext{
${ }^{a}$ Department of Thoracic Surgery, Royal Brompton Hospital, Sydney Street, London SW3 6NP, UK,

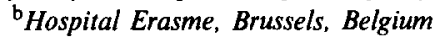

'Peter MacCallum Cancer Institute, Melbourne, Australia

${ }^{\mathrm{d}}$ Centre Hospital, Univversity de Liege, Liege, Belgium

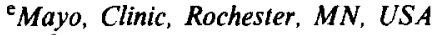

${ }^{f}$ Hopital Tenon, Paris, France

${ }^{8}$ Massachusetts General Hospital, Boston, MA, USA

${ }^{\mathrm{h}}$ Washington University Medical Center, St. Louis, MO, USA

${ }^{i}$ Serv. de chirurgie thoracique, Paris, France

jUniversity of Michigan, Ann Arbor, MI, USA

${ }^{k}$ National Navy Medical Center, Bethesda, MD, USA

${ }^{\prime}$ Medical Academy, Gdansk, Poland

${ }^{\mathrm{m}}$ Academy Ziekenhuis Rotterdam, Rotterdam, The Netherlands

"Initut Gustave-Roussy, Villejuif, France

${ }^{\circ}$ Polyclinique de Courlancy, Reims, France

$\mathrm{P}_{A-Z}$ Vrije Universiteit Brussell, Jette, Belgium

${ }^{q}$ University of Limburg, Maastricht, The Netherlands
}

In making its recommendations the Group set out a number of objectives.

(a) Any staging protocol should be simple and widely applicable, without being limited to the lowest common demoninator.

(b) The staging protocol should be sequential and logical, avoiding unnecessary tests which might prove expensive and invasive.

(c) The staging protocol proceeds to identify patients suitable for treatment with curative intent since there is no purpose to staging for palliative therapy.

(d) The staging protocol should be applicable to good clinical practice with all

\footnotetext{
फै Pretreatment minimal staging for non-small cell lung cancers: a consensus report. Goldstraw $P$ et al. Lung Cancer 1991; 7: 7-9.
} 
forms of therapy. There would be no restriction on institutional preference for additional investigations, nor additional requirements for trial purposes.

In making its recommendations the group made the following assumptions.

(a) Any staging protocol would be TNM based (UICC or AJC equivalent)

(b) The staging protocol covered only non-small cell lung cancer (NSCLC)

(c) No recommendations were made regarding which groups might be appropriate for different forms of therapy. This was deemed to be the domain of individual clinicians and their institutions.

(d) We assumed that the diagnosis already had been established.

(e) Patient suitability should be separately assessed, and we assumed that each patient was fit for all forms of therapy.

The staging protocol involves 3 steps, as outlined in the following tables.

\section{Step I}

\begin{tabular}{llll}
\hline Investigation & Patient group & Confirmatory tests \\
\hline $\begin{array}{l}\text { Clinical history } \\
\text { (to include) }\end{array}$ & $\begin{array}{l}\text { Weight loss and } \\
\text { performance status }\end{array}$ & All patients & As appropriate \\
$\begin{array}{l}\text { Clinical examination } \\
\text { Chest radiographs }\end{array}$ & PA & All patients & $\begin{array}{l}\text { As appropriate } \\
\text { Aspiration of effusion } \\
\text { (considered positive if } \\
\text { cytology malignant) } \\
\text { As for high risk patients } \\
\text { in Step II }\end{array}$ \\
Blood tests & Lateral & All patients & \\
& Hb & & \\
& Alk Phos & & \\
& Transaminase & & \\
& LDH & & \\
\hline
\end{tabular}

If still thought suitable for curative therapy proceed to Step II.

\section{Step II}

\begin{tabular}{lll}
\hline Investigation & Patient group & Confirmatory tests \\
\hline Bronchoscopy & $\begin{array}{ll}\text { All patients with central } \\
\text { tumours or those in whom } \\
\text { central extension is suspected }\end{array}$ & $\begin{array}{l}\text { The features of proximal, extrin- } \\
\text { sic compression are unreliable } \\
\text { and require further evaluation of } \\
\text { the mediastinum by CT and/or } \\
\text { mediastinal exploration }\end{array}$ \\
Bone scan & High risk group & $\begin{array}{l}\text { Skeletal X-rays } \pm \text { CT/MRI of } \\
\text { bone if dubious positive result }\end{array}$
\end{tabular}


CT chest and upper abdomen

(to lower pole of kidneys, with i.v. contrast enhancement of mediastinal vessels)

Liver ultrasound

Brain assessment by CT or MRI
All patients if available

Dubious findings confirmed (not necessarily histological)
High risk group ${ }^{a}$ if CT of abdomen not available

Advisable in high risk group ${ }^{a}$

- Unexplained anaemia $(\mathrm{Hb}<11 \mathrm{G} \%)$

- Unexplained weight loss ( $>8 \mathrm{lb}(3 \mathrm{~kg})$ in $6 / 12)$

- Abnormal alk phosphatase, or transaminase

- Where any clinical suspicion of metastatic disease

- Patients with stage III disease

${ }^{a}$ High risk patients are those having non-specific features identified by Hooper et al. (1987) Am Rev Respr Dis 118: 279.

If still thought suitable for curative treatment proceed to Step III.

\section{Step III}

(a) Bronchoscopy if not previously undertaken

(b) Thoracoscopy or video assisted

(c) Mediastinal exploration

- It is recommended that this is performed pre-operatively by

- Transcarinal aspiration

- Cervical mediastinoscopy

- Additional evaluation of the subaortic fossa by left anterior mediastinotomy

- This must be performed intraoperatively

- Palpation insufficient

- Careful and extensive mediastinal dissection

- Separate labeling as per Naruke or ATS of excised nodes for subsequent histological examination (only $\mathrm{N} 1$ nodes on resection specimen)

- Re-evaluation of $\mathrm{T}$ stage
All patients

If pleural effusion present, thoracoscopy cytology negative but clinical suspicion remains

Patients in whom CT suggests mediastinal invasion or if CT shows nodes $>1.0 \mathrm{cms}$

The above groups with tumours of the left upper lobe and left main bronchus

All paticnts - including those whose mediastinum has been assessed preoperatively 
Proceed with definitive therapy, which will be surgical resection in all but the most unusual circumstances.

\section{Postscript}

The Group considered other tests which may be of value but made no recommendations as these tests are not universally available or acceptable and require validation. 